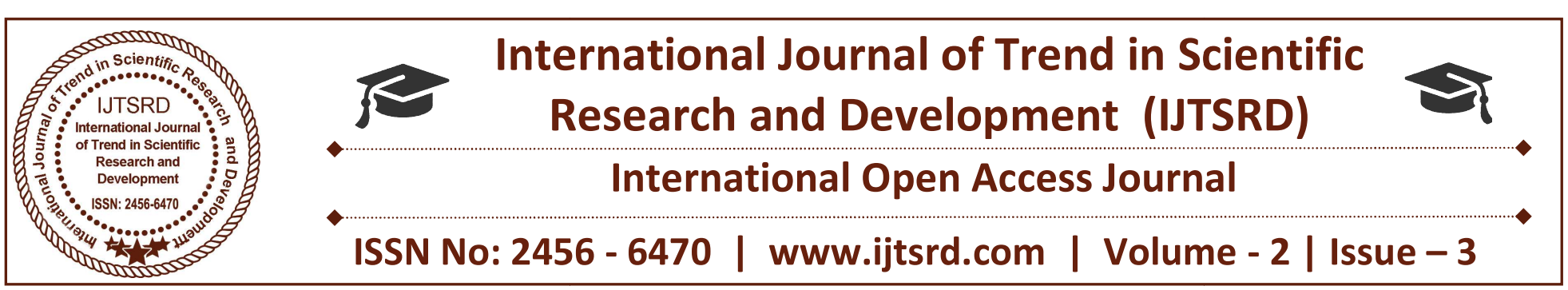

\title{
Autonomous Voice Control Pick and Place Rover
}

\author{
J. Antony Dujartin ${ }^{1}$, B. Vinoth Kumar ${ }^{1}$, K. Kamala Kanan ${ }^{1}$, E. Mukesh ${ }^{1}$, Mr. P. Devendran ${ }^{2}$ \\ ${ }^{1}$ UG Scholar, ${ }^{2}$ Associate Professor, \\ Department of Mechatronics Engineering, SNS College of technology (Autonomous), \\ Coimbatore, Tamil Nadu, India
}

\begin{abstract}
This project is to control the Robot for Application through the voice operated. This project is used to pick and place the objects by Robot Controller Application in the remote areas. Battery energy is used to give the power to robot because now a day's power demand is increased due to this power failure happen many times. We are using the voice control system to control the rover motion. This is achieved by using the Bluetooth module $\mathrm{HC}-05$ which creates a Bluetooth shield. Android application-(ARM apk) is created to encrypt the voice command into the pulse signal which will send the signal through the Bluetooth. HC-05 receives the encrypted electrical signal and processes this signal into suitable command to run rover. Here we are using the PIC $16 \mathrm{ff} 40$ pin developer board as a controller which process the signal and control the motor. LCD display is used to display what the command is given, we are using 9 command to control the rover which are pointed in the program.
\end{abstract}

Keywords: Wide Range Coverage and Voice Control Application

\section{INTRODUCTION}

The project is designed to control a robotic vehicle by voice commands for remote operation. An 8051 series of microcontroller is used together with a Bluetooth device interfaced to the control unit for sensing the signals transmitted by any Android application running cell phone. Remote operation is achieved by any smart-phone/Tablet having Android OS upon a GUI (Graphical User Interface) based voice operation. The transmitting end uses an Android application through which the voice commands are transmitted to digital bits. At the receiver end, these commands are used for controlling the robot to make it move forward, backward, left or right. At the receiving end, two motors are interfaced to the microcontroller where they are used for the movement of the vehicle. Serial communication data sent from the Android application is received by the Bluetooth receiver interfaced to the microcontroller. Furthermore, this project can be enhanced using DTMF technology. Using this technology we can control the robotic vehicle by using cell phone. This technology has advantages over long communication range as compared to RF technology.

\section{Methodology}

At initially the rover is booted with the PIC program to controller, based on the command given by the user through the android application. The apk send the signal to the PIC controller through the Bluetooth, controller receive the Bluetooth signal using the HC05 module. In proposed system we reduce the usage of loop in a program by changing into a switch conditions. Since automation is not feasible in the low budget so we changes this into an semi automation by adding voice command control system. Voice control system is achieved by using a Bluetooth shield module to interface mobile application. Mobile app is download from the play store and Google assistant encrypt the voice command into pulse signal, this pulse signal is transferred from AMR app to Bluetooth module. 


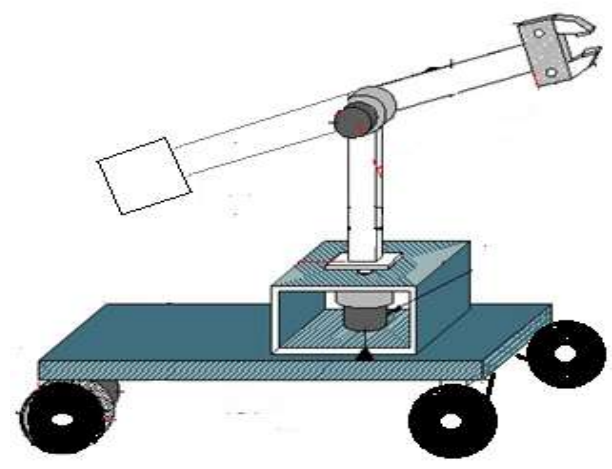

Fig . 1 PROPOSING SYSTEM

and substantially more $\mathrm{I} / \mathrm{O}$ sticks, a UART, A/D converter and significantly more highlights.

\section{B SERVO ROBOTIC GRIPPER}

It works under the principle of rack and pinion movement, a servo motor is attached in rack and the two pinion are jointed in parallel to each other as show in figure 2

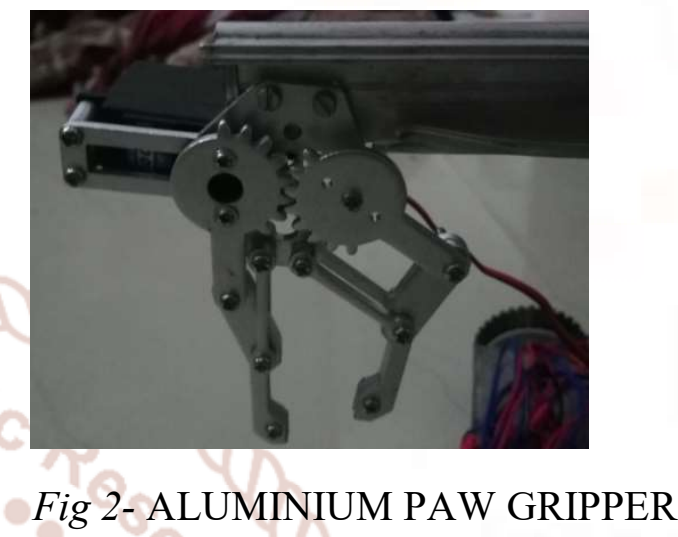

ELECTRICAL DESIGN LAYOUT:

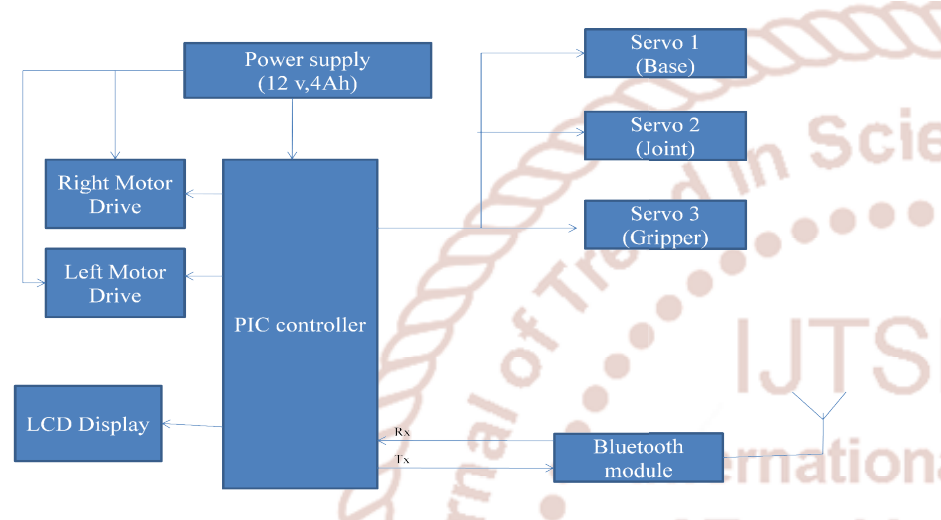

Fig 2 ELECTRICAL DESIGN LAYOUT

\section{Components}

The selection of materials involves the study of their Characteristics, advantages, availability, cost, user friendly property of components that we want to use. In our project, we select each and every components by study thoroughly about them. By proceeding like that only, we done our selection.

\section{A. PIC MICROCONTROLLER}

PIC is a Peripheral Interface Microcontroller which was produced in the year 1993 by the General Instruments Microcontrollers. It is controlled by programming and customized such that it performs diverse errands and controls an age line. PIC microcontrollers are utilized as a part of various new applications, for example, PDAs, sound embellishments and propelled restorative gadgets. There are numerous PICs accessible in the market extending from PIC16F84 to PIC16C84. These kinds of PICs are reasonable glimmer PICs. Microchip has as of late presented streak chips with various sorts, for example, 16F628, 16F877 and 18F452. The 16F877 costs double the cost of the old $16 \mathrm{~F} 84$, yet it is eight times more than the code estimate, with more RAM

\section{MOTOR DRIVE}

The ultrasonic wave is spread noticeable all around and hit the closest protest and reflected from the question which is gotten by the ultrasonic beneficiary. The got wave is given to enhancer to increase the got frail flag. After the enhancement the opened up wave is given to zero modification enhancer in light of the fact that the intensified wave is in the scope of over $6 \mathrm{v}$ level. At that point the yield is given to comparator in which the wave flag is changed over into relating square wave flag. At that point the square wave flag is given to contribution of the microcontroller. Presently the microcontroller analyzes the time between the transmitted flag and got flag and creates the comparing beat yield which is equivalent to separation of the question. Since it is realized that sound goes through air at around $344 \mathrm{~m} / \mathrm{s}(1129 \mathrm{ft} / \mathrm{s})$, you can set aside the ideal opportunity for the sound wave to return and duplicate it by 344 meters (or 1129 feet) to locate the aggregate round-trip separation of the sound wave. Round-trip implies that the sound wave voyaged 2 times the separation to the question before it was distinguished by the sensor; it incorporates the 'trek' from the sonar sensor to the protest AND the 'excursion' from the protest the Ultrasonic sensor (after the sound wave ricocheted off the question). To discover the separation to the question, basically partition the round-trip remove into equal parts. 
distance $=\frac{\text { speed of sound } \times \text { time taken }}{2}$

\section{DC MOTOR}

A rigging engine is a particular sort of electrical engine that is intended to create high torque while keeping up a low pull, or low speed, engine yield. Rigging engines can be found in various applications, and are most likely utilized as a part of numerous gadgets in your home. Gear engines are ordinarily utilized as a part of gadgets, for example, can openers, carport entryway openers, clothes washer time control handles and even electric wake up timers. Regular business utilizations of an apparatus engine incorporate healing facility beds, business jacks, cranes and numerous different applications that are beyond any reasonable amount to list. A equip engine can be either an AC (exchanging current) or a DC (coordinate current) electric engine. Most apparatus engines have a yield of between around 1,200 to 3,600 cycles for every moment (RPMs). These kinds of engines likewise have two distinctive speed details: typical speed and the slow down speed torque particulars.

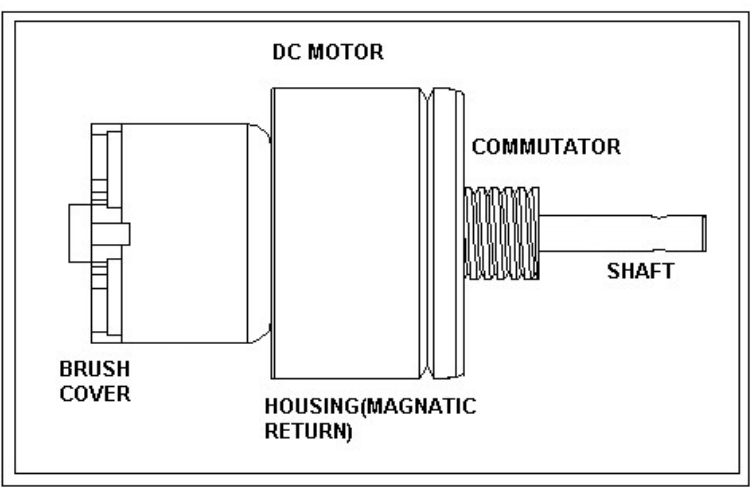

Fig 7 DC GEAR MOTOR

\section{E. SERVO MOTOR}

A servomotor is a rotary actuator that allows for precise control of angular position, velocity and acceleration. It consists of a suitable motor coupled to a sensor for position feedback. It also requires a relatively sophisticated controller, often a dedicated module designed specifically for use with servomotors. Servomotors are not a specific class of motor although the term servomotor is often used to refer to a motor suitable for use in a closed-loop control system. Servomotors are used in applications such as robotics, CNC machinery or automated manufacturing.

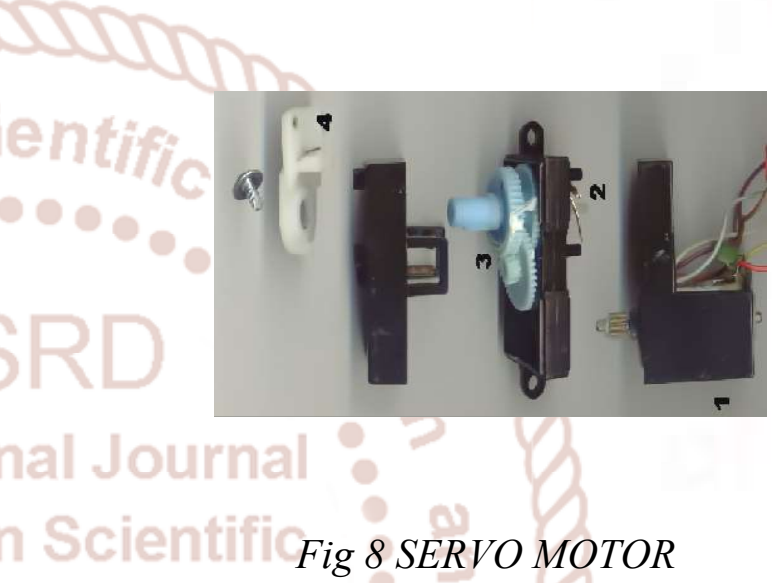

\section{F. BATTERY}

Battery is use for putting away the vitality created from the sun based power. The battery utilized is a lead-corrosive compose and has a limit of $12 \mathrm{v}$; 2.5A.the most reasonable optional cell is the lead corrosive cell and is broadly utilized for business purposes. A lead corrosive cell when prepared for utilize contains two plates submerged in a weaken sulphuric corrosive (H2SO4) of particular gravity around 1.28.the positive plate (anode) is of Lead peroxide $(\mathrm{PbO} 2)$ which has chocolate dark coloured shading and the negative plate (cathode) is lead $(\mathrm{Pb})$ which is of dim shading. At the point when the cell supplies momentum to a heap (releasing), the synthetic move that makes put frames lead sulfate (PbSO4) on both the plates with water being shaped in the electrolyte. After a specific measure of vitality has been pulled back from the cell, the two plates are Transformed into a similar material and the particular gravity of the electrolyte (H2so4) is lowered the cell is then said to be released. there are a few techniques to find out whether the cell is released or not. To charge the cell, coordinate current is gone through the cell in the invert bearing to that in which the phone 
gave current. This switches the concoction procedure and again shapes a lead peroxide $(\mathrm{PbO} 2)$ positive plate and an unadulterated lead $(\mathrm{Pb})$ negative plate. In the meantime, (H2so4) is shaped to the detriment of water, restoring the electrolyte (H2so4) to its unique condition. The compound changes that Occur amid releasing and reviving of a lead-corrosive cell.

\section{G. WHEEL}

A wheel is a round about part that is expected to pivot on a hub. The wheel is one of the fundamental parts of the haggle which is one of the six basic machines. Wheels are additionally utilized for different purposes, for example, a ship's wheel, directing haggle. Wheels, in conjunction with axles enable substantial items to be moved effectively encouraging development or transportation while supporting a heap, or performing work in machines. Regular cases are found in transport applications. A wheel enormously diminishes erosion by encouraging movement by moving together with the utilization of axles. With the end goal for wheels to pivot, a minute should be connected to the wheel about its hub, either by method for gravity, or by utilization of another outside power.

\section{FABRICATION}

In figure 9 shows the photograph of the mechanical setup arrangement. We designed this model using the AutoCAD and construct the mechanical frame using the mild steel in workshop.

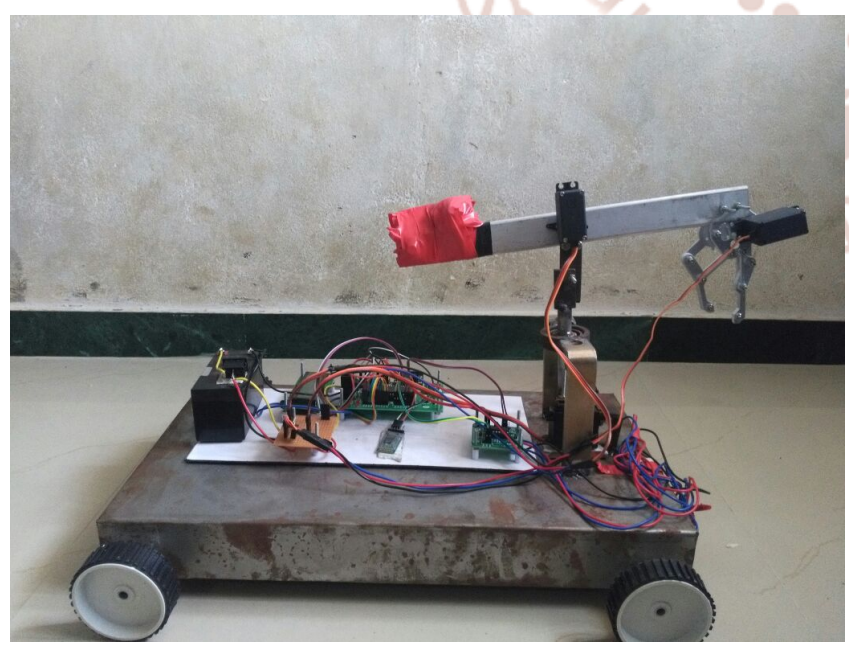

Fig 9 MECHANICAL SETUP

\section{RESULT \& CONCLUSION}

In this chapter we are going to discuss about the results that we experienced while fabricating this project. We mainly concentrated on Cost and power efficient project, likewise we are able to achieve some of the following results from the prototype.

We are using total 9 command to control the rover -

- Forward-Both the wheel move forward direction time taken by the Bluetooth module to receive the signal is 2 second.

- Reverse-Both the wheel move backward direction since it's an continuous process the wheel move backward until the next command is given.

- Turn Left-Left wheel move backward and right wheel move forward.

- Turn Right- Right wheel move backward and forward wheel move forward.

- Stop-Both the wheel will be stop.

- Pick up-Servo2 move to +45 degree and gripper servo close the finger.

- Place-Servo2 move to -45degree and gripper servo open the finger.

- Left-Arm move to the left side i,e Servo1 move to +90 degree.

- Right- Arm move to the right side i,e Servo1 move to -90 degree.

These are results mentioned above. Some of the errors we faced in the programming part are rectified by our project guide. We are using trail and error method to design the rover man problem we faced was stability of Arm and gripper. The whole prototype was able to be accomplished in a couple of months but the fabrication of gripper is not feasible and table so we purchased in online. However we accomplished within the deadline and we are able to run test runs, error checks, etc.

\section{ACKNOWLEDGMENT}

We take immense pleasure in expressing our humble note of gratitude to our project guide Mr.P.Devendran Assistant Professor Department of Mechatronics Engineering for his remarkable guidance in doing our project. 
International Journal of Trend in Scientific Research and Development (IJTSRD) ISSN: 2456-6470

\section{REFERENCE}

1) Control of an omni-directional robotic vehicle with Mecanum wheels-Telesystems Conference, 1991. Proceedings. Vol.1., NTC '91., National.

2) Anonymous, 2000. Land en tuinbouwcijfers 2000 [in Dutch]. LEI/CBS, 's Gravenhage, The Netherlands.

3) Arima, S. and Kondo, N. 1999. Cucumber harvesting robot and plant training system. Journal of Robotics and Mechatronics, 11(3):20821.

4) Boyse, J.W. 1979. Interference detection among solids and surfaces. Communications of the ACM, 22(1):3-9.

5) Craig, J.J. 1989. Introduction to Robotics, Addison-Wesley, Reading: Mass., USA.

6) Edan, Y. 1995. Design of an autonomous agricultural robot. Applied Intelligence, 5:41-50.

7) Gieling, Th.H., Van Henten, E.J., Van Os, E.A., Sakaue, O., and Hendrix, A.T.M. 1996. Conditions, demands and technology for automatic harvesting of fruit vegetables. Acta Horticulturae, 440: 360-365.

8) J. Connell, S. Mahadevan, "Rapid task learning for real robots" in Robot Learning, MA, Boston:Kluwer Academic, pp. 105-139, 1993.

9) S. Engelson, Passive Map Learning and Visual Place Recognition, Yale University, 1994

10) E. Nakano, N. Koyachi, "An Advanced Mechanism of the Omni-Directional Vehicle (ODV) and Its Application to the Working Wheelchair for the Disabled", Proc. of '83 Int. Conf. Advanced Robotics, pp. 277-284, 1983.

11) M. West, H. Asada, "Design and Control of Ball Wheel Omnidirectional Vehicles", Procs. of 1995 IEEE Int. Conf. on Robotics and Automation, vol. 2, pp. 1931-1938, 1995-May

12) A. Nishikawa, M. West, H. Asada, "Development of a Holonomic Omnidirectional Vehicle and an Accurate Guidance Method of the Vehicles", J. of the Robotics Society of Japan, vol. 13, no. 2, pp. 249-256, 1995.
13) K. Watanabe, Y. Shiraishi, J. Tang, T. Fukuda, S. G. Tzafestas, "Construction of the Dynamic Model for an Omnidirectional Mobile Robot", Procs. of CESA'96 IMACS Multiconference Symposium on Robotics and Cybernetics, pp. 643647, 1996-July.

14) K. Watanabe, Y. Shiraishi, "A PID control system for an omnidirectional mobile robot", Procs. of the 35th SICE Annual Conference Domestic Session Papers, pp. 167-177, 1996-July.

15) A. Ilchmann, "Non-identifier-based high-gain adaptive control" in Lecture Notes in Control and Information Science, Berlin:Springer-Verlag, 1993.

16) K. Sato, K. Watanabe, "Robust PI Control System for an Omnidirectional Mobile Robot with Three Orthogonal-Wheel Assemblies", Proc. of JSME Kyushu Branch Memorial Conference, pp. 132134, 1997-Oct.

17) K. Watanabe, J. Tang, F. Han, "A Rotational Control for an Omnidirectional Mobile Robot Using a Fuzzy Modeling Approach", Procs. of the l4th Annual Conference of RSJ, pp. 53-54, 1996Nov.

18) K. Watanabe, Adaptive Estimation and Control, UK, Hertfordshire:Prentice-Hall, 1992.

19) K. Tanaka, Advanced Fuzzy Control, Tokyo:Kyoritsu-syuppan, pp. 95-192, 1994.

20) K. Watanabe, K. Izumi, J. Tang, F. Han, "Trajectory Control of an Omnidirectional Mobile Robot Using a Fuzzy Servo System", Proc. of the 2nd Int. Workshop on Advanced Mechatronics (IWAM'97), pp. 74-79, 1997-Dec.

21)K. Watanabe, "Stochastic Fuzzy Control (Theoretical Derivation)", JSME Int. Journal, vol. 40, no. 2(C), pp. 224-230, June 1997.

22) K. Watanabe, K. Izumi, F. Han, "Stochastic Fuzzy Servo Control Using Multiple Linear Dynamic Models", Procs. of 2nd Int. Conf. on Knowledgebased Intelligent Electronic Systems, 1998-April. 